\title{
A wireless sensors architecture for efficient irrigation water management
}

\author{
H. Navarro-Hellín ${ }^{\mathrm{a}, *}$, R. Torres-Sánchez ${ }^{\mathrm{b}}$, F. Soto-Valles ${ }^{\mathrm{c}}$, C. Albaladejo-Pérez ${ }^{\mathrm{a}}$, \\ J.A. López-Riquelme ${ }^{\mathrm{c}}$, R. Domingo-Miguel ${ }^{\mathrm{d}}$ \\ a Widhoc Smart Solutions S.L., Parque Tecnológico de Fuente Álamo, CEDIT, Carretera del Estrecho-Lobosillo Km 2, 30320 Fuente Álamo, Murcia, Spain \\ b Ingeniería de Sistemas y Automática Department, Universidad Politécnica de Cartagena, Campus Muralla del Mar, Doctor Fleming, s/n 30202, Cartagena, \\ Murcia, Spain \\ c Tecnología Electrónica Department, Universidad Politécnica de Cartagena, Campus Muralla del Mar, Doctor Fleming, s/n 30202, Cartagena, Murcia, Spain \\ d Producción Vegetal Department, Universidad Politécnica de Cartagena, Paseo Alfonso XIII, 48, 30203 Cartagena, Murcia, Spain
}

\section{A R T I C L E I N F O}

\section{Article history:}

Available online $\mathrm{xxx}$

\section{Keywords:}

Remote monitoring

Wireless sensors

GPRS communication

Water optimization

Irrigation management

\begin{abstract}
A B S T R A C T
Water is an essential resource for the development of agriculture. In several locations like the southeast of Spain water is scarce and its cost is high, so optimal management of this important resource is essential. Therefore, the application of irrigation strategies to improve the watering process, affects the profitability of crops quite significantly. It is necessary to carry out the instrumentation of the variables that affect the growing process of the crop (soil, water and plant) and use the techniques associated with this instrumentation to take actions to optimize the production. The system proposed in this paper uses information and communication technologies, allowing the user to consult and analyze the information obtained by different sensors from any device (computer, mobile phone or tablet) in an easy and comfortable way. The proposed architecture is based on different wireless nodes equipped with GPRS connectivity. Each wireless node is completely autonomous and makes use of solar energy, giving it virtually unlimited autonomy. Different commercial sensors for measuring the wide range of parameters of the soil, plant and atmosphere can be connected to the nodes. The data is sent and processed on a remote server, which stores the information of the sensors in a database, allowing further consultation and analysis of data in a simple and versatile way.
\end{abstract}

(C) 2014 Elsevier B.V. All rights reserved.

\section{Introduction}

Irrigated agriculture is the biggest consumer of freshwater in arid and semi-arid zones, with a share of around $70-80 \%$ of the total volume of used water.

However, increased demand for water by other sectors and weather-associated limitations (increasing aridity as a result of climate change), suggests that the water resources available for agriculture in forthcoming decades will be lower in both quantity and quality. At the same time, new growers with lower production costs than the traditional ones in these areas are forcing them to reduce costs by lowering their main inputs. It is in this area of costs reduction where the efficient use of the water is becoming an increasingly important consideration, sometimes at the expense of

\footnotetext{
* Corresponding author. Tel.: +34 968197583.

E-mail address: hono.navarro@widhoc.com (H. Navarro-Hellín).
}

crop quality. However such issues must be addressed if such crops are to remain competitive. It is a proven reality that in semiarid zones the limited availability of water has contributed to creating increasing interest in water conservation, particularly among practitioners of irrigated agriculture. For these and other reasons, the scientific- and technical-based irrigation scheduling of water to maintain and even improve yield and quality has been and will remain a major challenge for irrigated agriculture (Puerto et al., 2013).

In recent years, the incorporation of sensors in the context of agricultural production for water management and conservation has received an increasing interest for establishing irrigation management strategies, such as regulated deficit irrigation (RDI) or partial root drying (PRD). Both strategies allow very significant increases in irrigation water productivity (yield produced per unit of irrigation water applied), especially in woody crops (Egea et al., 2009; Jones, 2004; Puerto et al., 2013). However, these strategies need several sensors to estimate the plat water status. 
Most common sensors to estimate plant water status are soil sensors, since they provide important information that is familiar to the user. These sensors provide data of the matric potential ( $\Psi_{\mathrm{m}}$, soil water status) or volumetric soil water content $\left(\theta_{\mathrm{v}}\right.$, soil moisture). Over the years, these sensors have evolved significantly since the first manual gauges that measured the pressure of the soil water to become ever more effective and precise in measuring the soil's water status and moisture content, integrating communication with dataloggers (Fereres and Goldhamer, 1990; Hanson and Edwards, 2000).

In addition to these sensors, measures to control the volume or concentration of soluble salts in the irrigation water have often been used in irrigated agriculture, especially in arid and semi-arid areas. Water electrical conductivity (EC) is important, and irrigation water can be classified as running from excellent $\left(\mathrm{EC} \leq 250 \mu \mathrm{S} \mathrm{cm}^{-1}\right)$ to unsuitable (EC $\geq 3000 \mu \mathrm{S} \mathrm{cm}^{-1}$ ) (James et al., 1982). Moreover, it has been demonstrated that the crop production decreases as the EC of the irrigation water increases (Maas and Hoffman, 1977). The overall EC (or quality) of the used water can be adjusted by using water from different sources, which explains the use of sensors that provide measurements of the volume and quality of water held in reservoirs.

This type of sensor provides useful data for regulating the conditions required by each of these irrigation strategies. These sensors have been used in conjunction with instrumentation systems to control the irrigation process, traditionally with wired dataloggers. In recent years, the quick development of wireless sensor networks (WSNs) has led to the use of sensor equipment with very little wiring, and great improvements in their installation and maintenance (Hussain, 2012; Khan et al., 2014; Nolz et al., 2013; Ruiz-Garcia et al., 2009; Yu et al., 2013). Wireless sensor networks are composed of different measuring points, called nodes, able to communicate wirelessly. The data obtained from each one of them, is stored in a sink node and processed for managing irrigation.

The ultimate aim is to use the data from field sensors towards a fully automatic irrigation system. Although a fully automatic system has not yet been achieved, remote irrigation management is possible by means of routers and Internet connections that access the data collected by dataloggers (wired) or by the sink nodes (WSNs) (Puerto et al., 2013). The common point of these systems is that they have a centralized communication structure, that is, they depend on a device (gateway) to communicate with the user, which can lead to connection problems for the whole system if such a device has limited connectivity.

Advances in mobile networks and cheaper Internet communications (GSM/GPRS, 3G) has led in recent years to the incorporation of modules that provide WSNs with access to mobile networks by using machine-to-machine (M2M) modules. This feature provides more flexibility in the installation, as it is not limited by the connectivity of the sink node or datalogger. Each node contains a mobile communication module (GSM/GPRS, 3G) changing the topology of the network from centralized to distributed. One of the important advantage of this approach is that a connection failure at a node does not affect the normal operation of the network. However, the higher energy requirements of the mobile communications network represent a complex challenge for the design and dimensioning of the instrumentation of the nodes (Sinduja and Sowmya, 2013).

This article describes the design and dimensioning of a wireless node to fulfill the specified requirements of autonomy and reliability, allowing an easy installation and the ability to use the wide range of electrical interfaces in agronomic sensors. The results obtained in different agricultural scenarios are then used to verify the operation of the equipment and the goodness of the agronomic data.

\section{Materials and methods}

\subsection{Hardware description}

One of the most important aspects to consider when designing a device for monitoring any kind of variable is the ability to cover a wide range of significant parameters for the monitored activity that will provide the device with the versatility necessary for use in a broad variety of real situations. Such measurements are provided by specific sensors that are connected to the device by means of a wide range of possible connection interfaces.

In the present article, a completely autonomous device for estimating the plant water status in several scenarios is presented. The device, which must be compatible with a wide variety of sensors that provide plant-related data, is based on a modular structure that consists of several electronic interconnected boards:

1. An electronic board, the Main-Board, which has already been used in other applications, including oceanographic monitoring by means of a ZigBee network (Albaladejo et al., 2012). This board is responsible for sensors' data. It is also in charge of communication with the rest of the boards and ensures that the whole system is working properly.

2. The Sensor-Board provides the interface with the connected sensors. The design of the board is optimized for agricultural monitoring, allowing the simultaneous connection of a common precision agriculture sensors.

3. The GPRS-Board is in charge of establishing the communication with the mobile network by means of a GSM/GPRS protocol, sending the data to the remote storage server for further consultation.

\subsection{Control, management and data collection subsystem}

Fig. 1 shows the flow diagram of the Main-board. When it is powered up, the microcontroller obtains the configuration information from the SD-Card. This card contains information about the sensors connected to the Sensor-Board, the sample period and transmission rate, the GPRS and remote server configurations, etc. By simply modifying a few files, the user is able to completely change the behaviour of the system, providing great flexibility. As soon as the configuration is initialized, the system enters in a sleep mode in which the power consumption kept below $600 \mu \mathrm{A}$. When the sample rate time has expired, the microcontroller is "woken up" by an interrupt signal and the process of retrieving the information from the sensors starts. This process is carried out by the interface board. Then, the microcontroller obtains the time from the RTC and stores all the information in the SD-Card. Next, the system enters the sleep mode again and waits for another interrupt. When the sending rate time has expired, the Main-Board establishes communication with the GPRS-Board to send the information obtained from the sensors to the remote server. This board also performs a charging algorithm to optimize battery life, activating and deactivating a circuit in the Sensor-Board with the purpose of connecting the solar panel only when the battery is outside a specified voltage range.

\subsection{Sensor interface subsystem}

The Sensor-Board is one of the most important parts of the whole system since it provides the interfaces that will determine compatibility with external sensors. Given that the SDI-12 interface is one of the most important and standardized interfaces in the field of precision agriculture (López et al., 2009), it provides great flexibility because a wide range of commercial sensors used in agriculture are compatible with it. According to the technical characteristics 


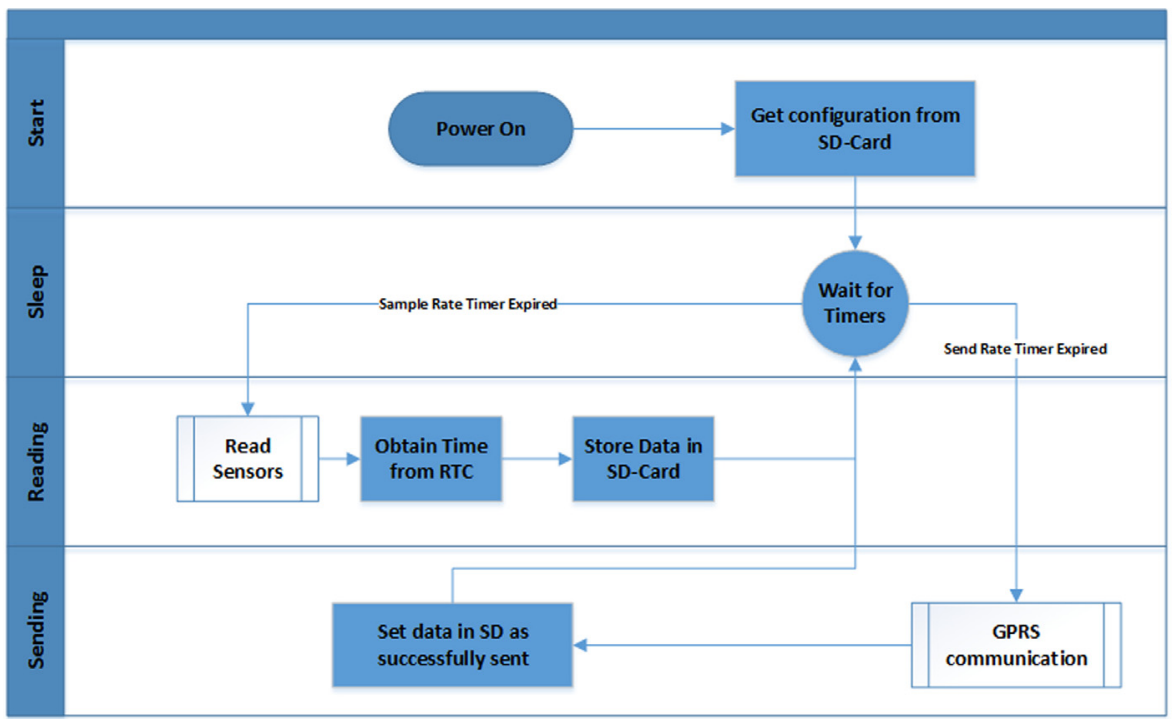

Fig. 1. Flow diagram of the Main-Board.

of the SDI-12 protocol (SDI-12, 2005). The sensors that use SDI-12 are powered at $12 \mathrm{~V}$. As the battery operates in the range of 3.7-4.2 V, a $12 \mathrm{~V} \mathrm{DC/DC}$ converter was included to power every sensor connected to the Sensor-Board, while a $5 \mathrm{~V}$ DC/DC was used to power the tri-state buffer needed for the SDI-12 interface. This power source could also be used to power up sensors. The rest of the sensor interfaces included in this board were:

- One 4-20 mA interface.

- Three voltage interface.

- One digital pulse interface.

Fig. 2 presents the flow diagram of the Sensor-Board. In the initial state, the power supplies of the sensors are inactive. As soon as the Main-Board enters the reading state, the Sensor-Board warms the sensors for $2 \mathrm{~s}$, then starts reading all the SDI-12 sensors, after which it begins reading the analogue sensors. Finally the MainBoard stores the data in the SD-Card and the Sensor-Board enters the Initial State again.

\subsection{Communication subsystem}

The communication module is based on the SIM900 GSM/GPRS chip from Simcom Ltd. The SIM900 module communicates with the Main-Board by mean of AT-Commands through a serial interface. The decision to use GSM/GPRS technology rather than the more modern $3 G$ or even $4 \mathrm{G}$ is based on two important points:

1. GSM/GPRS is more established than any other mobile technology, so its coverage is greater than that of its counterparts. Also, the vast majority of the areas that need to be monitored for precision agriculture will be located in the countryside, where 3G/4G is not always available.

2. Although GPRS/GSM technology is much slower than $3 \mathrm{G} / 4 \mathrm{G}$, the amount of data collected at each sampling is so small that speed is not an issue. Moreover the power consumption of devices compatible with $3 \mathrm{G} / 4 \mathrm{G}$ is much greater than in the case of GPRS/GSM - an aspect that is much more important than speed in scenarios where the autonomy of the device is of key importance.

This module is one of the most important parts of the device and allows a change in the topology commonly used in WSN, from centralized to distributed. A sink or a gateway node is not needed as every device in the network has its own capacity to transmit data by Internet. Fig. 3 shows the flow diagram of the communication subsystem. As the Main-Board enters the Sending state, the GPRS module is powered up and tries to establish connection with the remote server through the mobile network. If the communication with the remote server is established successfully, the GPRS-Board enters the Sending state, in which the data is processed and sent to the server separately in bursts of $1 \mathrm{kB}$. If any problem occurs during this process, the GPRS will enter the inactive mode to save the battery. In this case, the GPRS-Board will try to transmit all the data at the next sending time.

Fig. 4a shows the completely assembled device. In order to guarantee the stability of the network, an installation protocol must be followed. Firstly, an analysis of the signal power at the point of installation is performed for each mobile operator by means of an Anritsu MS2713E spectrum analyzer. The operator with the strongest signal will be the most suitable. Using the most suitable GPRS antenna is very important, since the sensitivity of the Sim900 module is around $-109 \mathrm{dBm}$ (SIM 900 Hardware Design Guide, 2010). If the threshold cannot be reached with an internal antenna of $2 \mathrm{~dB}$, a $5 \mathrm{~dB}$ external antenna should be used instead. This protocol ensures high quality GSM/GPRS communications under normal working conditions.

The electronics are located inside an IP-67, a box of reduced dimensions $(120 \mathrm{~mm} \times 122 \mathrm{~mm} \times 75 \mathrm{~mm})$, whose cover is transparent so that the solar panel inside is protected from exposure to the weather (Fig. 4b).

\subsection{Experimental sites}

Four experimental tests were carried out to analyze the behaviour of the device in real scenarios. The data was collected from January 2014 onwards in four commercial plantations located in the south-east of Spain. In order to manage the irrigation, soil moisture sensors rather than plant based sensors were used because soil moisture information is generally more familiar to the farmers. The control variables were matric potential $\left(\Psi_{\mathrm{m}}\right)$ and volumetric soil water content $\left(\theta_{\mathrm{v}}\right)$ which are common in the irrigation management. The criteria for scheduling irrigation used in the scenarios 1, 2 and 3 (see below) were decided by the farmer. In scenarios 1 and 2 the aim was maintain soil moisture conditions equivalent or close to field capacity to satisfy the maximum crop water requirements. In the third scenario soil moisture 


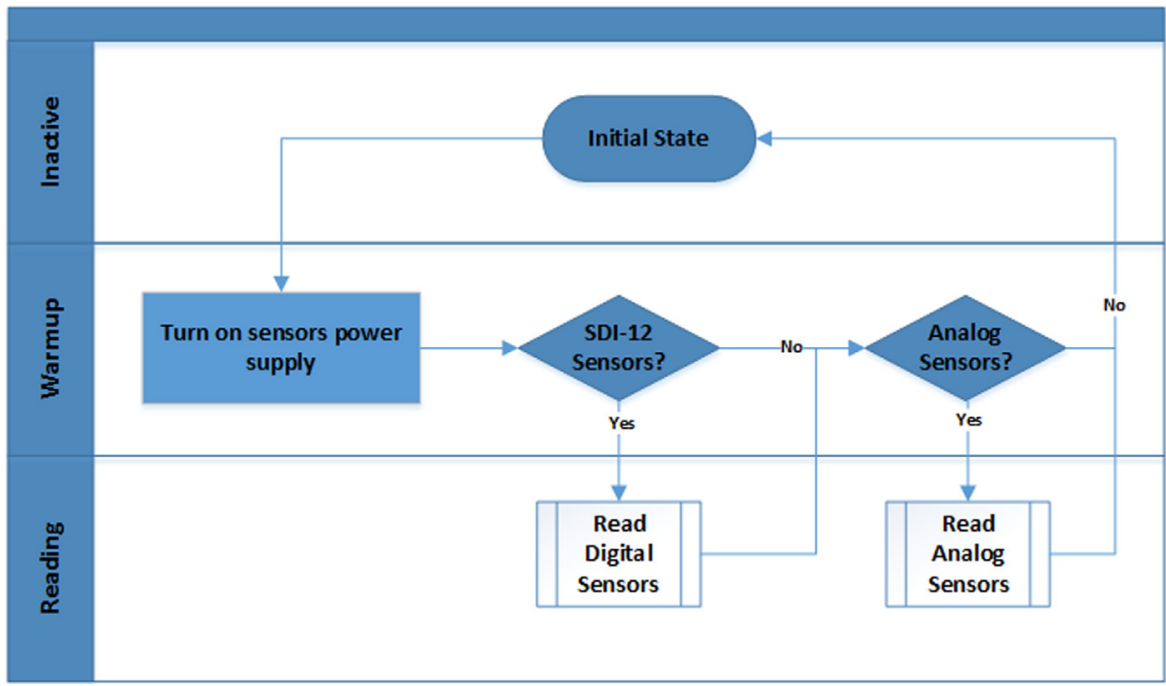

Fig. 2. Flow diagram of the Sensor-Board.

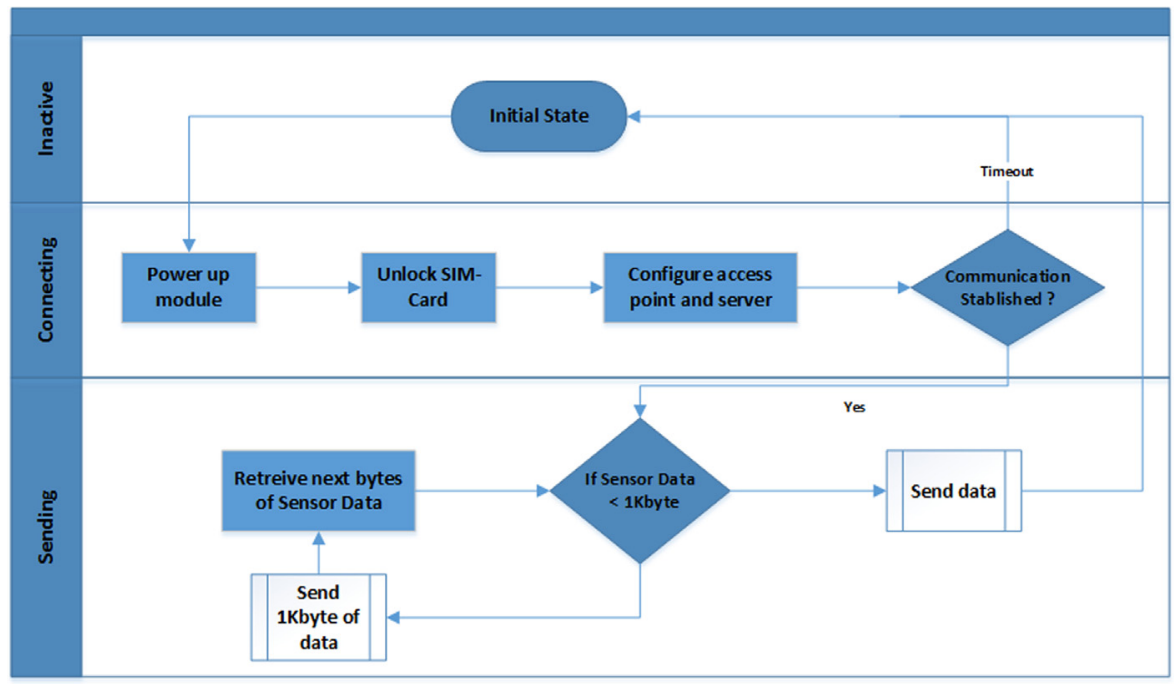

Fig. 3. Flow diagram of the communication subsystem.

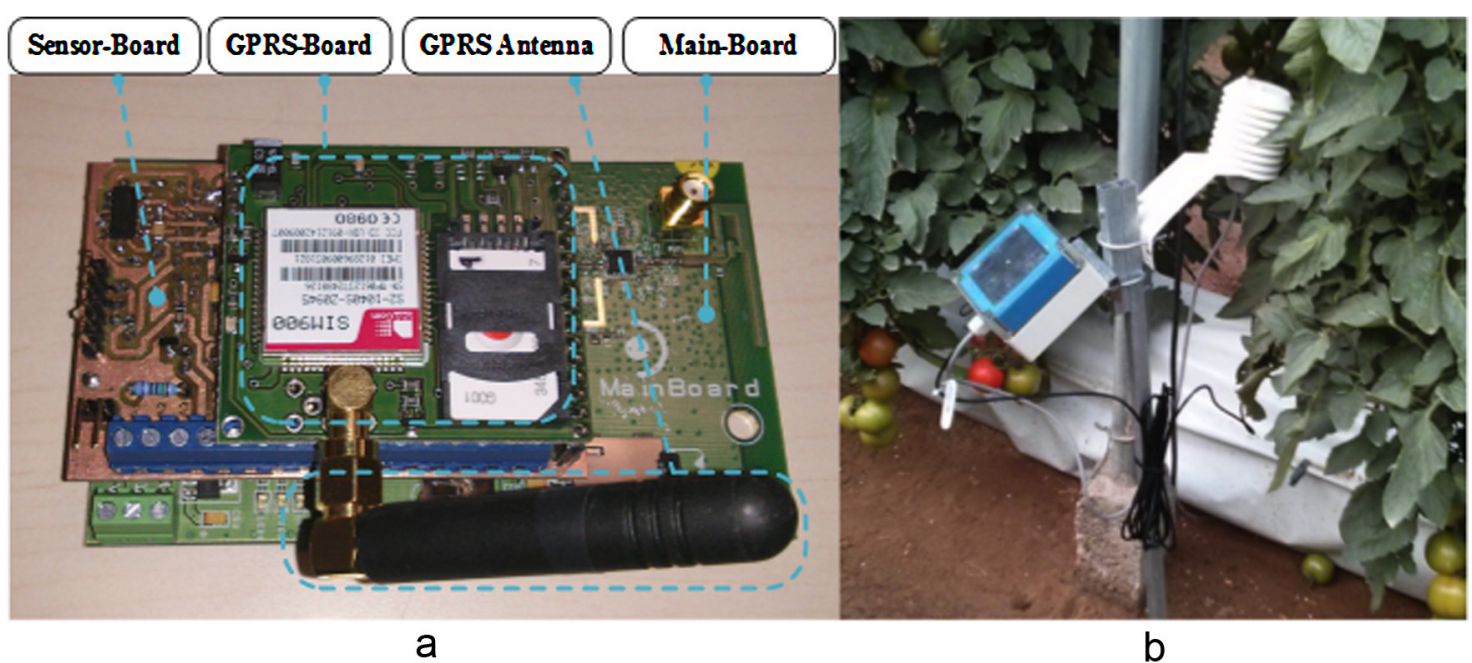

Fig. 4. (a) Assembled device and (b) installed device. 
Table 1

Summary of the sensors used and their technical specifications.

\begin{tabular}{|c|c|c|c|c|c|c|c|c|}
\hline Sensor & Measured data & Output & Range & Resolution & Accuracy & $\begin{array}{l}\text { Supply voltage } \\
\text { range }\end{array}$ & Power & URL \\
\hline $10 \mathrm{HS}$ & Soil moisture & $0.3-1.25 \mathrm{~V}$ & $0-57 \%$ VWC & $0.08 \%$ VWC & $\pm 3 \%$ VWC & $3-15$ VDC & $15 \mathrm{~mA}$ & http://www.decagon.com/ \\
\hline HP II & $\begin{array}{l}\text { Moisture, } \\
\text { conductivity and } \\
\text { temperature }\end{array}$ & SDI-12 & $\begin{array}{l}0-100 \% \text { VWC } \\
0.01-1.5 \mathrm{~S} / \mathrm{m} \\
-10^{\circ} \text { to }+65^{\circ} \mathrm{C}\end{array}$ & $\begin{array}{l} \pm 0.3 \% \text { VWC } \\
\pm 0.0014 \mathrm{~S} / \mathrm{m} \\
\pm 0.6^{\circ} \mathrm{C}\end{array}$ & $\begin{array}{l} \pm 3 \% \mathrm{VWC} \\
\pm 0.0014 \mathrm{~S} / \mathrm{m} \\
\pm 0.6^{\circ} \mathrm{C}\end{array}$ & $9-20 \mathrm{VDC}$ & $30 \mathrm{~mA}$ & http://www.stevenswater.com/ \\
\hline MPS-2 & $\begin{array}{l}\text { Soil matric } \\
\text { potential and } \\
\text { temperature }\end{array}$ & SDI-12 & $\begin{array}{l}-10 \text { to }-500 \mathrm{kPa} \\
-40^{\circ} \text { to }+50^{\circ} \mathrm{C}\end{array}$ & $\begin{array}{l}0.1 \mathrm{kPa} \\
0.1^{\circ} \mathrm{C}\end{array}$ & $\begin{array}{l} \pm 25 \% \text { (from } \\
-10 \mathrm{kPa} \text { to } \\
-100 \mathrm{kPa})\end{array}$ & $6-15 \mathrm{VDC}$ & $10 \mathrm{~mA}$ & http://www.decagon.com/ \\
\hline GS3 & $\begin{array}{l}\text { Moisture, } \\
\text { conductivity and } \\
\text { temperature }\end{array}$ & SDI-12 & $\begin{array}{l}0-100 \% \text { VWC } \\
0-23 \mathrm{dS} / \mathrm{m} \\
-40^{\circ} \text { to }+50^{\circ} \mathrm{C}\end{array}$ & $\begin{array}{l}0.1 \% \mathrm{VWC} \\
0.001 \mathrm{dS} / \mathrm{m} \\
0.1^{\circ} \mathrm{C}\end{array}$ & $\begin{array}{l} \pm 3 \% \mathrm{VWC} \\
\pm 1 \mathrm{dS} / \mathrm{m} \\
\pm 1{ }^{\circ} \mathrm{C}\end{array}$ & 3.6-15 VDC & $30 \mathrm{~mA}$ & http://www.decagon.com/ \\
\hline LMK & Pressure & $4-20 \mathrm{~mA}$ & $0 \ldots 10 \mathrm{mH}_{2}$ & $0.003 \mathrm{mH}_{2}$ & $\pm 0.05 \mathrm{mH}_{2}$ & $8-32$ VDC & $20 \mathrm{~mA}$ & http://www.sensotec-instruments.com/ \\
\hline ES-2 & $\begin{array}{l}\text { Water electrical } \\
\text { conductivity and } \\
\text { temperature }\end{array}$ & SDI-12 & $\begin{array}{l}0-120 \mathrm{dS} / \mathrm{m} \\
-40^{\circ} \text { to }+50^{\circ} \mathrm{C}\end{array}$ & $\begin{array}{l}0.001 \mathrm{dS} / \mathrm{m} \\
0.1^{\circ} \mathrm{C}\end{array}$ & $\begin{array}{l} \pm 0.01 \mathrm{dS} / \mathrm{m} \\
\pm 0.1^{\circ} \mathrm{C}\end{array}$ & 3.6-15 VDC & $0.5 \mathrm{~mA}$ & http://www.decagon.com/ \\
\hline
\end{tabular}

conditions depended on the crop phenological stage. In general, $\Psi_{\mathrm{m}}$ was used to decide the irrigation frequency and $\theta_{\mathrm{v}}$ to adjust the gross irrigation doses. In scenario 3 it was decided to use a GS3 sensor instead of the 10HS because of its robustness, accuracy and easier installation for it to be in close contact with the substrate. Table 1 summarizes the main characteristics of the sensors used. The different scenarios are described below.

Scenario 1 (woody crop). Fino lemon trees (Citrus limon L. Burm. fil cv. 49.) on C. macrophylla Wester, growing in a soil with a low water retention capacity, were irrigated in order to optimize the use of the irrigation water based on the information provided by the sensors. The soil had a sandy clay loam texture and the irrigation water had an electrical conductivity (EC) of $2200 \mu \mathrm{S} \mathrm{cm}^{-1}$. The orchard consisted of 10 year old lemon trees. Tree spacing was $7.0 \mathrm{~m} \times 5.5 \mathrm{~m}$, with an average ground coverage of about $47 \%$. Two drip irrigation lines ( $0.8 \mathrm{~m}$ apart $)$ were used for each tree row. There were 4 emitters $\left(4 \mathrm{Lh}^{-1}\right)$ on both sides of each tree. Two sensor nodes were installed in the 5.5 ha orchard, each one with a soil matric potential sensor (MPS-2, Decagon devices, Inc., Pullman, WA 99163, USA) at a depth of $30 \mathrm{~cm}$ and three soil moisture sensors at a depth of 20, 40 and $80 \mathrm{~cm}$ (10-HS, Decagon devices, Inc., Pullman, WA 99163, USA) located $25 \mathrm{~cm}$ from a representative dripper and $2.25 \mathrm{~m}$ from the trunk. The device automatically took readings of the soil matric potential and volumetric water content every $15 \mathrm{~min}$.

Scenario 2 (vegetable crop). Endive plants were planted in beds with $1.0 \mathrm{~m}$ centres. There were two rows per bed, and plants were spaced $35 \mathrm{~cm}$ apart within the row (triangular planting). A single lateral tube with $0.2 \mathrm{~m}$ between emitters and a discharge rate of $5 \mathrm{Lh}^{-1}$ was used to meet their water requirements. The irrigation water had an electrical conductivity (EC) of $800 \mu \mathrm{S} \mathrm{cm}^{-1}$. One sensor node was installed in the 2.5 ha plot with two soil matric potential sensors (MPS-2, Decagon devices, Inc., Pullman, WA 99163, USA) at depths of 17 and $35 \mathrm{~cm}$, and one FDR sensor at a depth of $20 \mathrm{~cm}$ (Hydra Probe II, Stevens Water Monitoring Systems, Inc., Portland, OR, USA) located $20 \mathrm{~cm}$ from a representative dripper and $20 \mathrm{~cm}$ from the plant.

Scenario 3 (greenhouse soilless culture). The test was carried out in a plastic greenhouse (800 gauge) using hydrangeas growing in $12 \mathrm{~L}$ plastic pots containing a substrate mixture (2 parts peat, 1 part coconut fibre and 1 part perlite by volume). The pots were spaced $50 \mathrm{~cm}$ apart within the row and with $60 \mathrm{~cm}$ between two contiguous rows. The irrigation was supplied using a single lateral line that had two compensating drippers $\left(2 \mathrm{Lh}^{-1}\right)$ per pot. The irrigation water had an EC of $800 \mu \mathrm{S} \mathrm{cm}^{-1}$. One sensor node with three GS3 sensors (Decagon devices, Inc., Pullman, WA 99163,
Table 2

Summary of the sensors used on each node.

\begin{tabular}{lllllll}
\hline \multirow{2}{*}{ Node type } & \multicolumn{6}{l}{ Sensors } \\
\cline { 2 - 7 } & 10HS & HP-2 & MPS-2 & GS3 & LMK807 & ES-2 \\
\hline Woody crop & 3 & 0 & 1 & 0 & 0 & 0 \\
Vegetable crop & 0 & 1 & 2 & 0 & 0 & 0 \\
Greenhouse soilless culture & 0 & 0 & 0 & 3 & 0 & 0 \\
Water reservoir & 0 & 0 & 0 & 0 & 1 & 1 \\
\hline
\end{tabular}

USA) was installed in the greenhouse with one GS3 sensor located mid-height in each pot.

Scenario 4 (water reservoir). The water reservoir monitored, with a $500 \mathrm{~m}$ perimeter and a total capacity of $52,000 \mathrm{~m}^{3}$, is used to irrigate different fields located nearby. The reservoir receives water from a desalination plant and several wells. To keep track of the water level and conductivity, a pressure sensor (LMK 807, Sensotec Incorporated, Columbus, $\mathrm{OH}$ ) and a conductivity sensor (ES-2, Decagon devices, Inc., Pullman, WA 99163, USA) were used. The pressure sensor was located at the bottom of the reservoir and the conductivity sensor $1 \mathrm{~m}$ below the water surface.

Table 2 summarizes the number and type of sensors connected to each node.

\subsection{Remote software storage management}

The information from the sensors connected to the device is periodically sent to a data server, where it is processed and stored in a relational database.

The software architecture of the data server is based around three main components: (1) an application developed in Java, which is in charge of communication with the nodes, (2) a relational database that stores the data, and (3) a Web application to check the information of the sensors.

Fig. 5 shows the architecture of the system from a functional point of view. The node, after sampling the connected sensors, establishes a TCP communication through the GSM/GPRS module with the Java application that is being executed in the server. Once the socket of the communication is established, the node sends the data in a specific format. The Java application manages each connection and even in cases of simultaneity, it receives and sends the information of each sensor to a MySQL database. The Web application is used to query the database to show selected data to the user.

The flow of the Java application is as follows: first, the header of the message, which contains information about the identification 

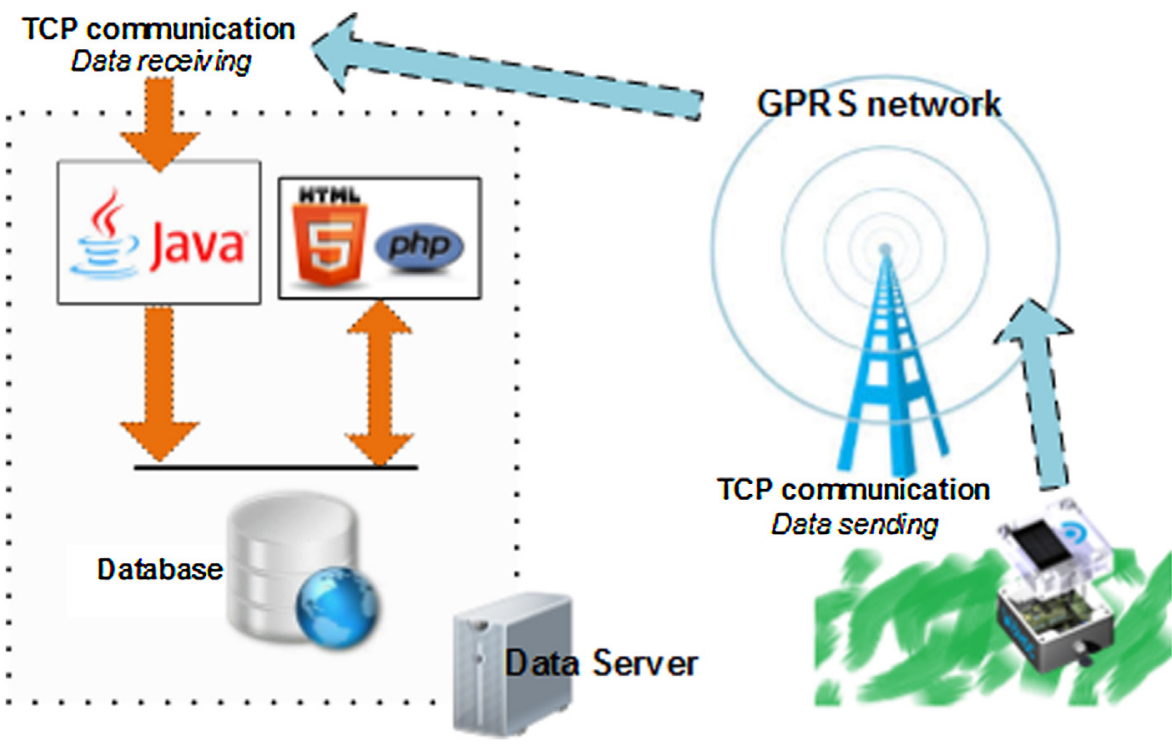

Fig. 5. Architecture of the system.

of the node, its sample rate, the location, the sensors connected, etc., is analyzed. Then, the sensor data is checked and processed and, if the information is below or above the threshold established by the user, an email is sent to warn of a possible incident. The data and the exact timestamp sent by the node are stored in the database, while the information gathered by the sensors is made available on the Internet through a website. This Web application is developed in HTML5, Javascript and PHP, as shown in Fig. 6. The top of the figure shows the geographic location of the devices and the connected sensors. The bottom of the figure shows, in graphic form, the information obtained from the sensors connected to the device. This allows the desired data to be visualized and the range of measurements and dates to be downloaded and expressed in $\mathrm{xml}$ format.

\section{Results and discussion}

\subsection{Agronomic results}

Fig. $7 a-c$ presents the data concerning the soil water content and water status of the crops recorded in the three commercial plantations and a water reservoir respectively. The first three figures clearly represent the evolution of $\theta_{\mathrm{v}}$ and $\Psi_{\mathrm{m}}$, while Fig. $7 \mathrm{~d}$ plots the evolution of the water conductivity and volume of the irrigation reservoir.

Fig. 7a shows how, as the season progresses, the moisture in the root zone of the lemon tree (top $50 \mathrm{~cm}$ ) increases, while at $80 \mathrm{~cm}$ it decreases slightly. The moisture content from 20 to $40 \mathrm{~cm}$ depth reflects the high availability of water for the crops, based on $\Psi_{\mathrm{m}}$

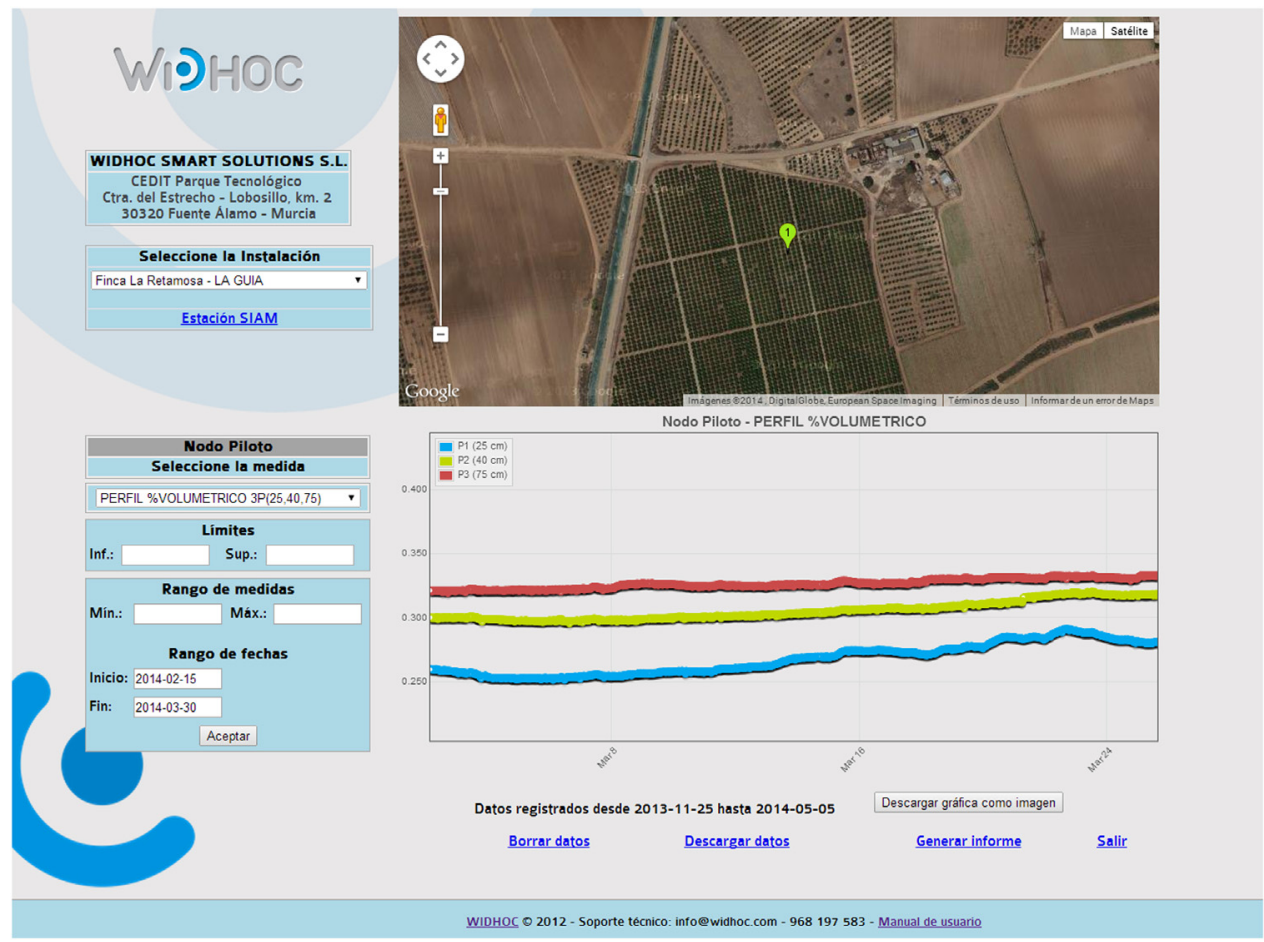

Fig. 6. Web application interface. 

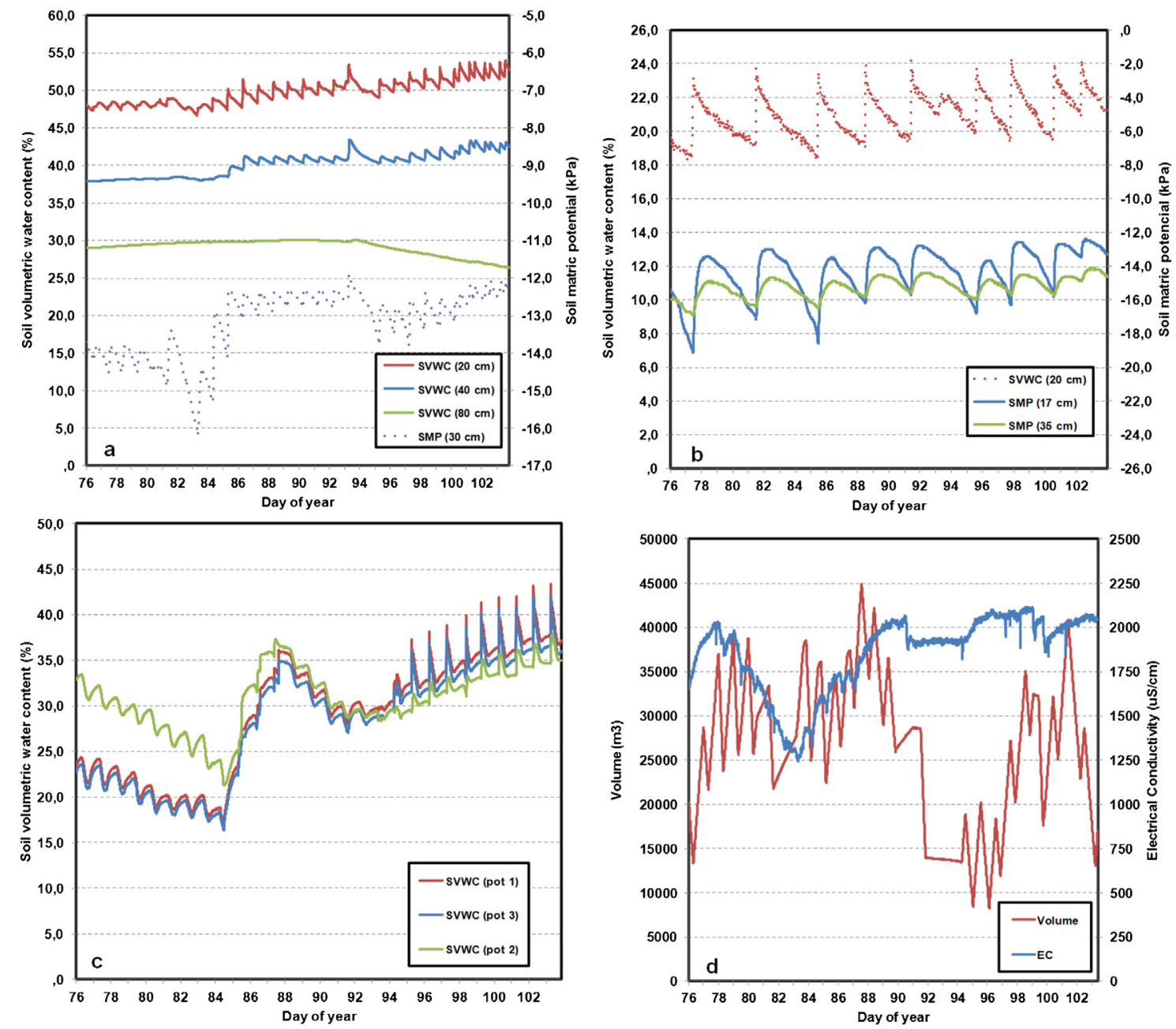

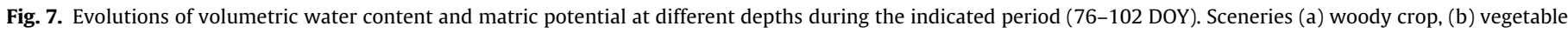

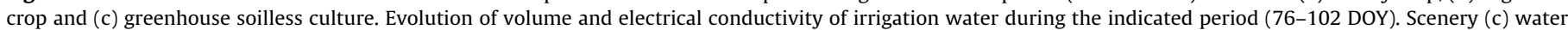
reservoir.

values at $30 \mathrm{~cm}$ (Domingo et al., 1996). The irrigation strategy is based on maintaining a high level of available water in the zone of highest root activity during the critical periods of flowering and fruit-setting, while optimizing the use of the irrigation water by minimizing deep percolation losses. The high frequency of strong winds $\left(>5 \mathrm{~m} \mathrm{~s}^{-1}\right)$ in the area were taken into consideration during the flowering periods. To ensure the availability of water in the top $50 \mathrm{~cm}$ of soil, two daily irrigations (instead of one) were applied after day 95 (Fig. 7a). The total amount of water applied in a growing season was $5775 \mathrm{~m}^{3} \mathrm{ha}^{-1}$ in contrast to the $6000 \mathrm{~m}^{3} \mathrm{ha}^{-1}$ applied by Domingo et al. (1996). These authors managed the irrigation according to the FAO methodology using a Class A evaporation pan. The climatic conditions, irrigation system and total yields were similar $\left(\approx 50 \mathrm{tha}^{-1}\right)$. The difference represents a water saving of $225 \mathrm{~m}^{3} \mathrm{ha}^{-1}$ with the irrigation controlled by sensors. However, the irrigation water quality and annual rainfall presented in the scenario 1 were lower than the ones presented by the previous authors $\left(2200 \mu \mathrm{Scm}^{-1}\right.$ vs $1250 \mu \mathrm{Scm}^{-1}$ and $100 \mathrm{~mm}$ vs $315 \mathrm{~mm}$ for the EC and rainfall, respectively). Considering that citrus fruits are salt sensitive (Storey and Walker, 1998) and bearing in mind the contribution from rain water, the savings could have been higher. Nevertheless, in order to choose one irrigation methods or the other, it would be necessary to keep registering the information during at least two more seasons.
Endive plant requires consistent levels of water (near reference demand levels) throughout its rapid growth and final development periods. Reductions in the available water during these growth periods can result in reduced leaf development (Maynard et al., 1999), so that it is important to maintain the moisture content of the soil near field capacity at depths where the root system is located practically throughout the growth cycle. Fig. 7b plots the last days of the crop cycle (DOY 76-103), illustrating the high $\Psi_{\mathrm{m}}$ values and the evolution dynamics of the $\theta_{\mathrm{v}}$. Soil moisture (Hydra Probe II) and soil matric potential sensors (MPS-2) show the high irrigation frequency and the little variation in the minimum humidity values reached, with a slight increasing trend close to harvesting. The information provided by these sensors was of great help for maintaining the moisture content of the soil at field capacity values at the depths explored by the root system of the crops.

Fig. 7c shows the evolution of the volumetric water content of the substrate measured in three different pots using a GS3 sensor inserted at mid-depth. As can be seen, there is no clearly defined pattern as the water content changes constantly. In the period 76-103 DOY, $\theta_{\mathrm{v}}$ gradually fell over 8 consecutive days before sharply increasing. This was followed by another reduction and then a permanent recovery. Regardless of the grower's irrigation procedure, Fig. 7c shows: (i) similar patterns in the water content evolution in the three pots located in different rows, (ii) rapid 


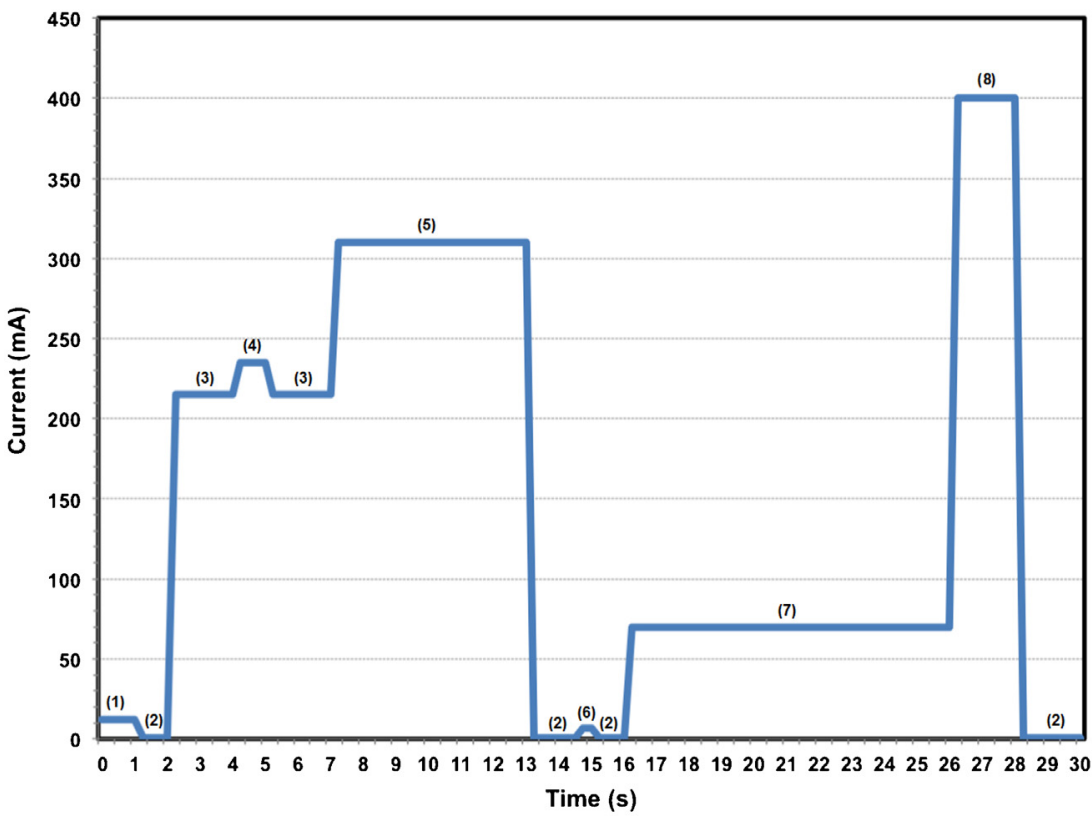

Fig. 8. Woody crop node power consumption.

drainage during the final period and (iii) noise-free representation in a substrate where others sensors might have contact problems. It must be taken into account that good soil drainage in this kind of cultivation practice is essential to avoid root rotting.

Fig. $7 d$ plots the water conductivity and volume of the irrigation reservoir used to irrigate several nearby fields. The ES-2 sensor used to measure the conductivity of the water is of key importance to maintain the water quality in the desired range. As shown in Fig. $7 \mathrm{~d}$, the value of the conductivity during the measurement period was below $2200 \mu \mathrm{S} \mathrm{cm}^{-1}$. The LMK 807 measured the volume during the same period. The variation in the EC was evident when taking water for irrigation or adding water from the wells and the desalination plant. The information shown in Fig. $7 d$ is of great help for mixing the water from the different sources to attain the conductivity required levels.

\subsection{Power and energy consumption results}

In order to analyze the power consumption of the device, an exhaustive energetic analysis of each scenario was carried out to determine the most suitable battery and solar panel needed to make the device energetically autonomous.

A detailed explanation about the power consumption of the woody crop node in the worst-case scenario, that is, a sample rate of $10 \mathrm{~min}$ and a sending rate of $1 \mathrm{~h}$, is given below.

The node has eight functional states, numbered as follows: (1) initialization and configuration, (2) standby, (3) interface warm-up, (4) digital sensor data acquisition, (5) analogue sensor data acquisition, (6) SD-Card data storage, (7) GPRS standby and (8) GPRS module transmission.

The measurements of the current reported in this paper were taken with a YOKOGAWA WT210 digital wattmeter and WTVIEWER software. Fig. 8 shows an example sequence of the power consumption of the node when the system is functioning. After initialization and configuration, the data are collected from the sensors, first from the digital sensors and finally from the analogue sensors. After that, the data is stored in the SD-Card. The sequence of states (3), (4), (5) and (6), is repeated every $10 \mathrm{~min}$ (sample rate). After $1 \mathrm{~h}$ (sending rate), all the sensor data collected before and available in the card are sent to the server. After that, the
Table 3

Current components and their description.

\begin{tabular}{|c|c|}
\hline Type of current & Description \\
\hline $\bar{I}_{\text {Standby }}$ & Current consumed in standby mode \\
\hline $\bar{I}_{\text {Initialization }}$ & $\begin{array}{l}\text { Current consumed in the process of initialization the GPRS } \\
\text { node }\end{array}$ \\
\hline $\bar{I}_{\text {Interface warm-up }}$ & $\begin{array}{l}\text { Current consumed with the current converters in active } \\
\text { mode }\end{array}$ \\
\hline $\bar{I}_{\text {Digital sensor }}$ & $\begin{array}{l}\text { Current consumed by digital sensors. One MSP-2 for } \\
\text { woody crop }\end{array}$ \\
\hline $\bar{I}_{\text {Analog sensor }}$ & $\begin{array}{l}\text { Current consumed by analogue sensors. Three HS10 for } \\
\text { woody crop }\end{array}$ \\
\hline $\bar{I}_{\text {Store memory }}$ & $\begin{array}{l}\text { Current consumed in the process of storing data in the } \\
\text { flash memory }\end{array}$ \\
\hline $\bar{I}_{\text {GPRS warm-up }}$ & $\begin{array}{l}\text { Current consumed in the process of establishing the } \\
\text { connection with the phone cell }\end{array}$ \\
\hline $\bar{I}_{\mathrm{GPRS} \text { send }}$ & Current consumed in sending of data to the server \\
\hline
\end{tabular}

system returns to standby mode, until the next scheduled reading process.

The ultimate aim of this study was to determine how much current the device consumes on average, so as to relate the resulting figure directly with the capacity of the batteries and hence determine the device's autonomy. The average current consumption of the GPRS node may be determined thus:

$$
\begin{aligned}
\bar{I}_{\text {Total }}= & \bar{I}_{\text {Standby }}+\bar{I}_{\text {Initialization }}+\bar{I}_{\text {Interface warm-up }}+\bar{I}_{\text {Digital sensor }} \\
& +\bar{I}_{\text {Analog sensor }}+\bar{I}_{\text {Store memory }}+\bar{I}_{\text {GPRS standby }}+\bar{I}_{\text {GPRS send }}
\end{aligned}
$$

Each of the current components is explained in Table 3. To calculate the autonomy of the node, worst-case scenarios were assumed for each measurement. Thus, expression (2) shows sensor system consumption in standby mode. Eq. (3) expresses the estimated average current consumed by the device in the process of initialization. Expressions (4)-(7) are calculated in the same way. The interval between samplings considered in this study was $10 \mathrm{~min}$, which is the worst-case scenario regarding energy consumption, although the average sampling period in real deployments is $15 \mathrm{~min}$. Expressions (8) and (9) are calculated in the same way. 


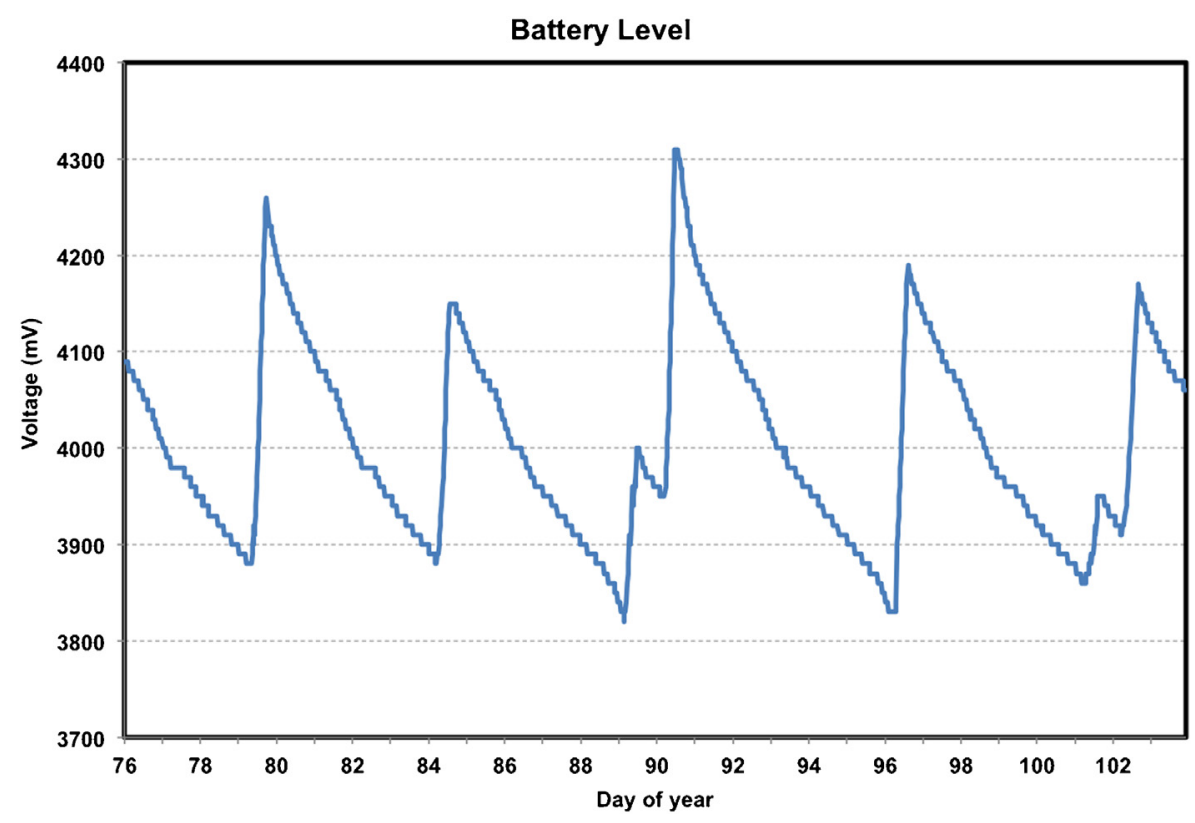

Fig. 9. Woody crop node battery voltage.

Considering an average current consumption of $5.93 \mathrm{~mA}$ (1), the next step is to choose a battery and a solar panel that enables the node to be completely autonomous. In order to achieve this, several tests were carried out with a wide spectrum of commercial batteries before the decision was made to use a LI103450A battery, a $1900 \mathrm{mAh}$ Li-ion rechargeable battery with a nominal voltage of $3.7 \mathrm{~V}$, equipped with a protection circuit that prevents overcharging as well as deep discharging. With this battery and considering the scenario presented, expression (10) estimates autonomy of the woody crop node without solar panels, which is around 13.35 days. The Sensor-Board has a circuit that manages the load based on the switching of an external solar panel. Using this battery in conjunction with a solar panel of $0.8 \mathrm{~W}$ (with a rated voltage of $5 \mathrm{~V}$ and a rated current of $160 \mathrm{~mA}$ ) will allow the node to be completely autonomous even under prolonged poor light condition.

$\bar{I}_{\text {Standby }}=0.6 \mathrm{~mA}$

$\bar{I}_{\text {Initialization }} \approx \frac{(12-0.6) \mathrm{mA} \times 1 \mathrm{~s}}{24 \times 3600 \mathrm{~s}}=0.132 \mu \mathrm{A}$

$\bar{I}_{D A / D C} \approx \frac{(215-0.6) \mathrm{mA} \times 4 \mathrm{~s}}{600 \mathrm{~s}}=1.429 \mathrm{~mA}$

$\bar{I}_{\text {Digital sensor }} \approx \frac{(235-0.6) \mathrm{mA} \times 1 \mathrm{~s}}{600 \mathrm{~s}}=0.390 \mathrm{~mA}$

$\bar{I}_{\text {Analog sensor }} \approx \frac{(310-0.6) \mathrm{mA} \times 6 \mathrm{~s}}{600 \mathrm{~s}}=0.394 \mathrm{~mA}$

$\bar{I}_{\text {Store memory }} \approx \frac{(7-0.6) \mathrm{mA} \times 0.5 \mathrm{~s}}{600 \mathrm{~s}}=5.333 \mu \mathrm{A}$

$\bar{I}_{\text {GPRS warm-up }} \approx \frac{(70-0.6) \mathrm{mA} \times 10 \mathrm{~s}}{3600 \mathrm{~s}}=0.192 \mathrm{~mA}$

$\bar{I}_{\mathrm{GPRS} \text { send }} \approx \frac{(400-0.6) \mathrm{mA} \times 2 \mathrm{~s}}{3600 \mathrm{~s}}=0.222 \mathrm{~mA}$

Number of days $\approx \frac{\text { Battery capacity }(\mathrm{mAh})}{\bar{I}_{\text {Total }}(\mathrm{mA}) \times 24 \mathrm{~h}}=\frac{1900 \mathrm{~mA} \times \mathrm{h}}{5.93 \mathrm{~mA} \times 24 \mathrm{~h}}$

$$
=13.35 \text { days }
$$

To test the selected battery and solar panel, a validation test was conducted over a period of four months (from January to April
2014). A woody crop node was set up in Miranda (Cartagena) in a 4 ha mandarin orchard. Fig. 9 shows in detail the voltage recorded over a period of 28 days in which the battery voltage was kept between the desired values thanks to the solar panel and the charging algorithm.

The consumption of all the nodes was also analyzed in Table 4. This Table 4 shows the mean power consumption of the device for the different scenarios, considering sampling rate values of between 10 and $60 \mathrm{~min}$ and sending rates from 1 to $12 \mathrm{~h}$. Logically, the higher the sampling rate, the more power the device needs to operate and so the power consumption is increased. Increasing the sample rate provides more information in less time. If the sending rate is reduced, the information will be available sooner but the device will be less efficient energetically as very few samples will be sent during each GSM/GPRS connection. After analyzing the table, it was concluded that the sending rate has a greater effect in scenarios where the power consumption of the sensors is low (Irrigation reservoir node, vegetable node); however, in scenarios where the sensors have a higher power consumption (woody crop node), the sending rate is of little importance for the overall power consumption of the device.

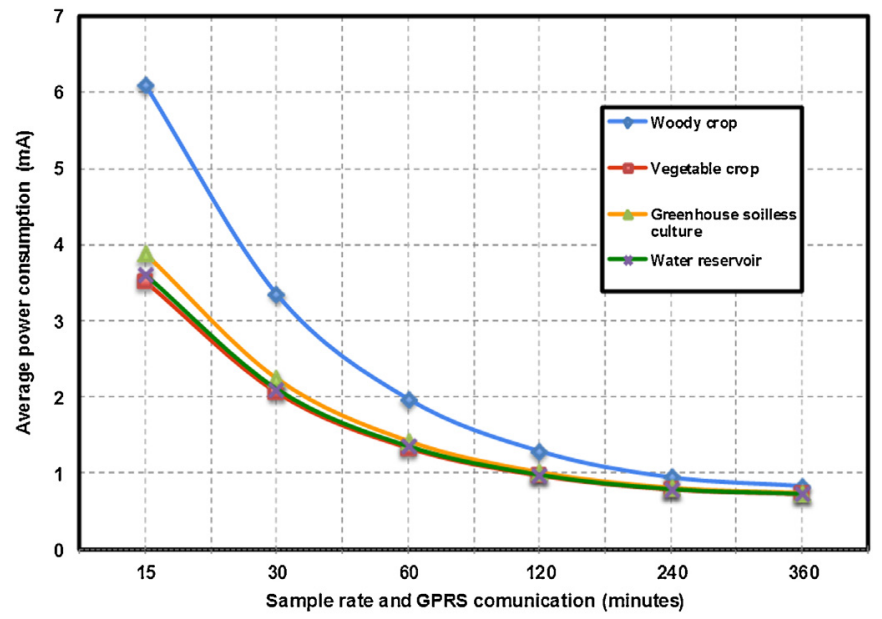

Fig. 10. Real time average power consumption. 
Table 4

Average power consumption of the device (mA).

\begin{tabular}{|c|c|c|c|c|c|c|c|c|}
\hline & & & \multicolumn{6}{|c|}{ Sample rate (min) } \\
\hline & & & 10 & 20 & 30 & 40 & 50 & 60 \\
\hline \multirow[t]{6}{*}{ Woody crop } & GPRS communication rate $(\mathrm{h})$ & 1 & 5.93 & 3.47 & 2.65 & 2.24 & 2.00 & 1.83 \\
\hline & & 2 & 5.73 & 3.27 & 2.45 & 2.04 & 1.79 & 1.63 \\
\hline & & 4 & 5.62 & 3.16 & 2.34 & 1.93 & 1.69 & 1.52 \\
\hline & & 8 & 5.57 & 3.11 & 2.29 & 1.88 & 1.64 & 1.47 \\
\hline & & 12 & 5.55 & 3.09 & 2.27 & 1.86 & 1.62 & 1.45 \\
\hline & & 24 & 5.54 & 3.08 & 2.26 & 1.85 & 1.60 & 1.44 \\
\hline \multirow[t]{6}{*}{ Vegetable crop } & GPRS communication rate $(\mathrm{h})$ & 1 & 2.06 & 1.54 & 1.36 & 1.28 & 1.22 & 1.19 \\
\hline & & 2 & 1.86 & 1.33 & 1.16 & 1.07 & 1.02 & 0.98 \\
\hline & & 4 & 1.75 & 1.23 & 1.05 & 0.97 & 0.91 & 0.88 \\
\hline & & 8 & 1.70 & 1.18 & 1.00 & 0.91 & 0.86 & 0.83 \\
\hline & & 12 & 1.68 & 1.16 & 0.98 & 0.90 & 0.84 & 0.81 \\
\hline & & 24 & 1.67 & 1.14 & 0.97 & 0.88 & 0.83 & 0.79 \\
\hline \multirow[t]{6}{*}{ Greenhouse soilless culture } & GPRS communication rate $(\mathrm{h})$ & 1 & 2.61 & 1.81 & 1.55 & 1.41 & 1.33 & 1.28 \\
\hline & & 2 & 2.41 & 1.61 & 1.34 & 1.21 & 1.13 & 1.07 \\
\hline & & 4 & 2.30 & 1.50 & 1.24 & 1.10 & 1.02 & 0.97 \\
\hline & & 8 & 2.25 & 1.45 & 1.18 & 1.05 & 0.97 & 0.92 \\
\hline & & 12 & 2.23 & 1.43 & 1.17 & 1.03 & 0.95 & 0.90 \\
\hline & & 24 & 2.22 & 1.42 & 1.15 & 1.02 & 0.94 & 0.88 \\
\hline \multirow[t]{6}{*}{ Water reservoir } & GPRS communication rate (h) & 1 & 2.20 & 1.61 & 1.41 & 1.31 & 1.25 & 1.21 \\
\hline & & 2 & 1.99 & 1.40 & 1.20 & 1.10 & 1.04 & 1.00 \\
\hline & & 4 & 1.89 & 1.30 & 1.10 & 1.00 & 0.94 & 0.90 \\
\hline & & 8 & 1.84 & 1.24 & 1.05 & 0.95 & 0.89 & 0.85 \\
\hline & & 12 & 1.82 & 1.23 & 1.03 & 0.93 & 0.87 & 0.83 \\
\hline & & 24 & 1.80 & 1.21 & 1.01 & 0.91 & 0.85 & 0.81 \\
\hline
\end{tabular}

In Table 4, the device sent multiple samples during each connection in order to optimize the battery in scenarios where real time is not necessary. Fig. 10 shows the current consumption of all the nodes for a sampling rate of $15 \mathrm{~min}$ and above, and in case that real time information is needed; that is, as soon as the sensor information is read, the data is sent to the server, so the information for the user is available in real time. In these scenarios, the power consumption increased in every case but was still acceptable given the specifications of the device.

\section{Conclusions}

This paper describes the design, optimization and development of a practical application to optimize water resources in irrigated agriculture by monitoring soil water status and the irrigation water. The article shows the technical challenges addressed in terms of WSNs and GSM/GPRS network communications, the sensors used and their configuration and energy optimization in a system based on a distributed architecture.

To highlight the effectiveness and accuracy of the developed system, several case studies have been presented with the aim of analyzing the behaviour of the device in real scenarios. It is concluded that the sensor nodes are of great help to reach the desired moisture conditions at the different depths and to maintain water electrical conductivity level of the irrigation reservoir at the desired value, thus contributing to the ability to adapt the irrigation strategy according to each situation.

The development of a small, compact and autonomous unit is of key importance for convenient use in agricultural facilities, so as not to interfere with field operations, avoid the theft of material and allow installation. To make the system compatible with commercial sensors, it has been necessary to adapt the device to the different interfaces adopted by sensors' vendors.

The sampling rate of the sensors and sending rate using a GPRS connection is important considerations when estimating the power consumption of the device. In the performed tests, the sampling rate was adjusted to $15 \mathrm{~min}$ and the sending rate to $30 \mathrm{~min}$. These rates are considered a good choice for correct agronomic decisions and for maintaining the complete autonomy of the device with an adequate battery and solar panel power.

\section{Acknowledgments}

The development of this work was supported by the Spanish Ministry of Science and Innovation (Ministerio de Ciencia e Innovación) (MICINN) through the projects MICINN, AGL201019201-C04-04 and MINECO, AGL2013-49047-C2-1-R. We would like to thank Widhoc Smart Solutions S.L. for letting us use their facilities to carry out the tests.

\section{References}

Albaladejo, C., Soto, F., Torres, R., Sánchez, P., López, J.A., 2012. A low-cost sensor buoy system for monitoring shallow marine environments. Sensors 12, 9613-9634, http://dx.doi.org/10.3390/s120709613.

Domingo, R., Ruiz-Sanchez, M.C., Sánchez-Blanco, M.J., Torrecillas, A., 1996. Water relations, growth and yield of Fino lemon trees under regulated deficit irrigation. Irrig. Sci. 16, 115-123, http://dx.doi.org/10.1007/BF02215619.

Egea, G., Pagán, E., Baille, A., Domingo, R., Nortes, P.A., Pérez-Pastor, A 2009. Usefulness of establishing trunk diameter based reference lines for irrigation scheduling in almond trees. Irrig. Sci. 27, 431-441, http://dx.doi.org/ 10.1007/s00271-009-0157-0.

Fereres, E., Goldhamer, D.A., 1990. Deciduous Fruit and Nut Trees. Agron, USA

Hanson, P.J., Edwards, N.T., 2000. Separating root and soil microbial contributions to soil respiration: a review of methods and observations. Biogeochemistry 48 115-146, http://dx.doi.org/10.1023/A: 1006244819642.

Hussain, R., 2012. Application of WSN in rural development, agriculture water management. Int. J. Soft Comput. Eng. 2, 68.

James, D.W., Hanks, R.J., Jurinak, J.J., 1982. Modern Irrigated Soils. John Wiley \& Sons, Inc., New York.

Jones, H.G., 2004. Irrigation scheduling: advantages and pitfalls of plant-based methods. J. Exp. Bot. 55, 2427-2436, http://dx.doi.org/10.1093/jxb/erh213.

Khan, A.W., Abdullah, A.H., Anisi, M.H., Bangash, J.I., 2014. A comprehensive study of data collection schemes using mobile sinks in wireless sensor networks. Sensors 14, 2510-2548, http://dx.doi.org/10.3390/s140202510.

López, J.A., Soto, F., Sánchez, P., Iborra, A., Suardiaz, J., Vera, J.A., 2009. Development of a sensor node for precision horticulture. Sensors 9, 3240-3255, http://dx.doi.org/10.3390/s90503240.

Maas, E.V., Hoffman, G.J., 1977. Crop salt tolerance - current assessment. J. Irrig Drain. Div. 103, 115-134.

Maynard, D.N., Hochmuth, G.J., Vavrina, C.S., Stall, W.M., Kucharek, T.A., Stansly, P.A., Taylor, T.G., Smith, S.A., Smajstrla, A.G., 1999. Lettuce, Endive, Escarole Production in Florida. HS., pp. 728. 
Nolz, R., Kammerer, G., Cepuder, P., 2013. Calibrating soil water potential sensors integrated into a wireless monitoring network. Agric. Water Manag. 116, 12-20, http://dx.doi.org/10.1016/j.agwat.2012.10. 002.

Puerto, P., Domingo, R., Torres, R., Pérez-Pastor, A., García-Riquelme, M., 2013. Remote management of deficit irrigation in almond trees based on maximum daily trunk shrinkage. Water relations and yield. Agric. Water Manag. 126, 33-45, http://dx.doi.org/10.1016/j.agwat.2013.04.013.

Ruiz-Garcia, L., Lunadei, L., Barreiro, P., Robla, I., 2009. A review of wireless sensor technologies and applications in agriculture and food industry: state of the art and current trends. Sensors 9, 4728-4750, http://dx.doi.org/10.3390/ s90604728.
SDI-12, 2005. SDI-12. A Serial-Digital Interface Standard for Microprocessor-Based Sensors, Version 1.3.

2010. SIM Hardware Design Guide. SIM 900 Hardware Design Guide v1.03.

Sinduja, R.M., Sowmya, S., 2013. Monitoring of rice crops using GPRS and wireless sensors for efficient use of water and electricity. Int. J. Appl. Innov. Eng. Manag. 2, 269-274.

Storey, R., Walker, R.R., 1998. Citrus and salinity. Sci. Hort. 78, 39-81, http://dx.doi.org/10.1016/S0304-4238(98)00190-3.

Yu, X., Wu, P., Han, W., Zhang, Z., 2013. A survey on wireless sensor network infrastructure for agriculture. Comp. Stand. Interfaces 35, 59-64, http://dx.doi.org 10.1016/j.csi.2012.05.001. 